\title{
Phosphaturic mesenchymal tumors among elderly patients: a case report and review of literature
}

\author{
Zaina Adnan1, David Nikomarov², Michal Weiler-Sagie³ and Noga Roguin Maor4 \\ ${ }^{1}$ Endocrinology and Metabolism Department, Zvulon Medical Center, Clalit Medical Health Care Services, Haifa, \\ Israel, 2 Orthopedic Surgery Department, 3 Michal Weiler-Sagie, Nuclear Medicine Department, Rambam Health Care \\ Campus, Haifa, Israel, and ${ }^{4}$ Clalit Medical Health Care and the Clinical Research Unit, Haifa and Western Galilee, \\ Haifa, Israel
}

Correspondence should be addressed to Z Adnan

Email

zainaad@clalit.org.il

\section{Summary}

Phosphaturic mesenchymal tumor (PMT) represents a rare cause of osteomalacia. The clinical signs and symptoms are vague and these lead to diagnosis delay. In the presence of hypophosphatemia and relatively high urine phosphate excretion, this entity should be taken into consideration in the deferential diagnosis of osteomalacia. In the present article, we report 81-year-old man presented to our clinic for evaluation due to osteopenia. His laboratory results disclosed hypophosphatemia, relatively increased urine phosphate excretion and increased level of intact fibroblast growth factor 23 (FGF23). A ${ }^{8}$ Gallium DOTATATE PET/CT revealed pathological uptake in the upper aspect of the left shoulder adjacent to the coracoid process. For suspected PMT a wide resection of the tumor was performed and pathological findings were consistent for PMT. Laboratory tests were normalized postoperatively. Reviewing the literature, we had identified 33 reported cases of PMTs among elderly patients age $\geq 70$ years. Unlike previously reported data, where tumors predominantly localized in the lower extremities and pelvis, our search disclosed a high rate of tumor localization (10 cases $-33.3 \%$ ) in the head with equal number of tumors (14 cases $-42.4 \%$ ) localized in the head and upper extremity as well as in pelvis and lower extremity. The present case describes unique tumor localization in an elderly patient and our literature search demonstrated for the first time a high rate of tumor localization in the head among this group of patients.

\section{Learning points:}

- PMTs represent a rare entity that should be considered in the differential diagnosis of elderly patients presented with persistent hypophosphatemia.

- Unlike previously reported data, head and neck tumor localization is frequent among elderly patients.

- ${ }^{68} \mathrm{G}$ allium-conjugated somatostatin peptide analogs, such as ${ }^{68} \mathrm{Ga}$-DOTATATE PET/CT demonstrated the greatest sensitivity and specificity for tumor localization in patients with phosphaturic mesenchymal tumors (PMTs).

- Wide tumor resection using intraoperative ultrasound is of major importance in order to ensure long-term cure.

\section{Background}

Osteomalacia $(\mathrm{OM})$ represents a metabolic disorder characterized by decreased mineralization of mature bone. Multiple causes underline this abnormality including inborn errors, chronic kidney disease and insufficient levels of vitamin $\mathrm{D}$ or calcium (1). Phosphaturic mesenchymal tumor (PMT) is an \footnotetext{
open Access (c) $\left(\begin{array}{l}\text { This work is licensed under a Creative Commons } \\ \text { Attribution-NonCommercial-NoDerivatives } 4.0\end{array}\right.$ International License.
}

uncommon cause of osteomalacia, usually manifests as a solitary benign neoplasm. Most of the tumors are located either in bone or soft tissue (2). The tumors are common in middle age individuals, although the age range may vary considerably with male to female ratio of $1.2: 1(3,4)$. 


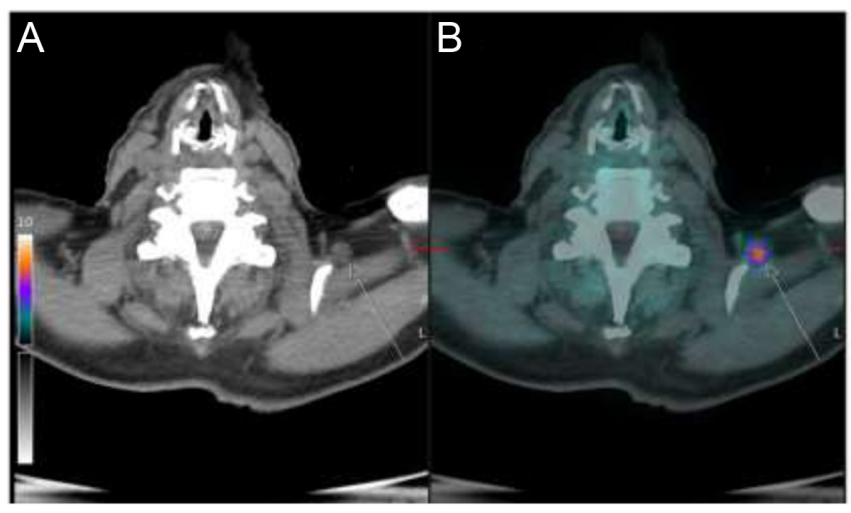

The clinical symptoms are vague. Therefore, diagnosis may last for up to 10 years. Weidner and Santa Cruz coined the term PMT in 1987. One of the clinical features of PMT is tumor-induced osteomalacia (TIO) characterized by bone pain, muscle weakness and pathological fractures; others may be without symptoms and only laboratory tests may disclose hypophosphatemia and hyperphosphaturia (5). Increased levels of fibroblast growth factor 23 (FGF23) and relative hyperphosphaturia in the presence of hypophosphatemia are important clues for suspecting PMT (6). Different imaging modalities are essential for tumor localizations. Surgery is curative and a wide resection with negative margins is of major importance for preventing recurrence (7).

PMT among elderly patients is relatively rare. The aim of this article is to report a case of PMT with extremely rare localization in a patient 81 years old and to review the literature focusing on published data regarding this entity among elderly patients.

\section{Case presentation}

An 81-year-old man was referred in 2014 to our clinic due to osteopenia with $\mathrm{T}$ score of -1.5 in the spine and -1.2 in the femur. He was treated previously by his family physician for 5 years with alendronate, vitamin D and calcium. In 2011, he was referred to orthopedic consultation for left hip pain. His physical examination and pelvic CT were normal. Medical history did not disclose any chronic diseases or hereditary bone disease apart from old bullet fragments in different body sites.

\section{Investigation}

Laboratory results since 2004 disclosed normal calcium levels $9.9 \mathrm{mg} / \mathrm{dL}$ (normal range: $8.8-10.20 \mathrm{mg} / \mathrm{dl}$ ), low blood phosphorus $2.10 \mathrm{mg} / \mathrm{dL}$ (normalrange: $2.5-5 \mathrm{mg} / \mathrm{dL}$ ),

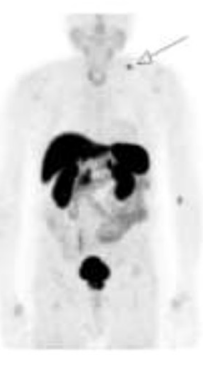

\section{Figure 1}

68GA-DOTATATE PET/CT shows normal biodistribution in the PET 3D maximal intensity projection $(C)$ with physiological uptake in the spleen, liver, kidneys and urinary bladder and pathological uptake in the left supraclavicular region (arrow). An axial slice at this level demonstrates a soft tissue nodule (arrow) on the CT portion of the study (A) that is located deep in the soft tissues, near the scapula, at the junction between the serratus anterior and supraspinatus muscles. The fusion axial image at this level (B) of the PET slice in color, and the CT slice beneath it in grayscale, demonstrates the high uptake in orange-purple in the nodule (arrow).

mild elevated alkaline phosphatase 144U/L (normal range: 30-120U/L), normal level of 25 hydroxyvitamin D $121 \mathrm{nmol} / \mathrm{l}$. Quantitative determination of 1,25 dihydroxyvitamin $\mathrm{D}(1,25(\mathrm{OH}) 2 \mathrm{D})$ in serum revealed a normal level 99 pmol/L (normal range: 39-160 pmol/L) using DiaSorin LIAISON XL in vitro chemiluminescent immunoassay (CLIA) performed on the LIAISON XL Analyzer. Intact FGF-23 was elevated $150.8 \mathrm{pg} / \mathrm{mL}$ (normal range: 23.2-95.4 pg/mL) using the same method. Repeated 24-h urine phosphate collection disclosed relatively high phosphate excretion $959 \mathrm{mg} / 24 \mathrm{~h}$ (normal range: $400-1300 \mathrm{mg} / 24 \mathrm{~h}$ ). For suspected PMT, ${ }^{68}$ Gallium DOTATATE PET/CT was performed and a pathological uptake in the upper aspect of the left shoulder adjacent to the coracoid process was observed. No mediastinal and axillary lymphadenopathy were observed (Fig. 1).

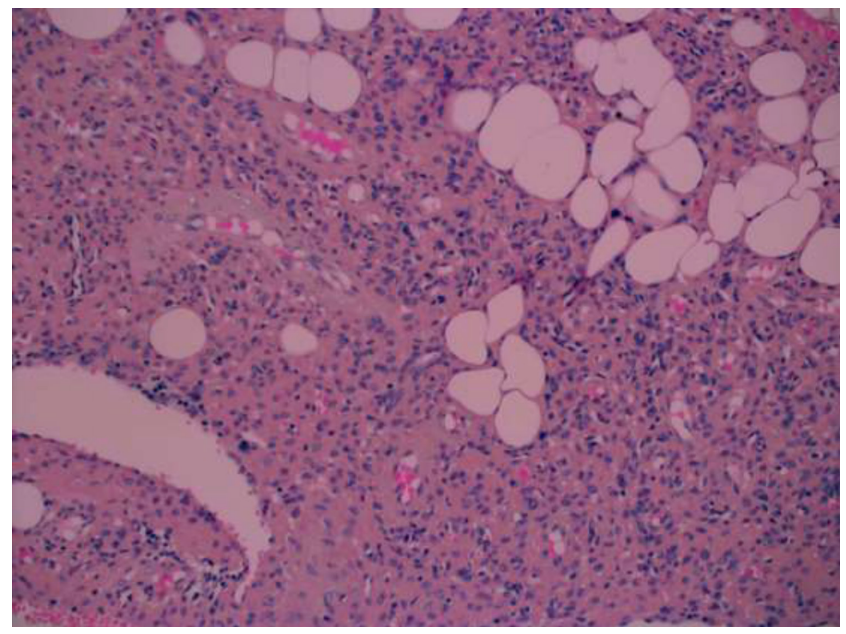

Figure 2

Fat tissue with proliferation of bland spindle cells, numerous blood vessels with amorphous matrix deposition and few calcifications without atypia and mitosis. The findings are consistent with benign phosphaturic mesenchymal tumor (stain, hematoxylin and eosin; original magnification, $\times 200$ ). 
Table 1 Elderly patient characteristics with phosphaturic mesenchymal tumor.

\begin{tabular}{|c|c|c|c|c|}
\hline $\begin{array}{l}\text { Authors and year of } \\
\text { publication }\end{array}$ & $\begin{array}{l}\text { No. of } \\
\text { cases }\end{array}$ & Age & Sex & Site of tumor \\
\hline Park et al. (13) & 1 & 76 & $\mathrm{~F}$ & Humerus \\
\hline Baronofsky et al. (14) & 1 & 72 & $\mathrm{~F}$ & Acetabulum \\
\hline \multirow[t]{4}{*}{ Folpe et al. (4) } & 4 & 73 & $\mathrm{M}$ & Hip \\
\hline & & 71 & $\mathrm{~F}$ & Forearm \\
\hline & & 77 & $\mathrm{~F}$ & Abdominal wall \\
\hline & & 80 & $M$ & Ischium \\
\hline Dupond et al. (15) & 1 & 71 & $\mathrm{M}$ & Mandible left \\
\hline Vollbrecht et al. (16) & 1 & 87 & $\mathrm{M}$ & Third metacarpal \\
\hline \multirow[t]{3}{*}{ Kenealy et al. (17) } & 3 & 79 & $\mathrm{~F}$ & Ethmoid sinus It \\
\hline & & 70 & $M$ & Extradural It \\
\hline & & 70 & $\mathrm{~F}$ & Ischium \\
\hline Yun et al. (18) & 1 & 71 & $\mathrm{~F}$ & Mandible lower with neck extension \\
\hline Savage and Zimmer (19) & 1 & 73 & $\mathrm{~F}$ & Pterygopalatine fossa \\
\hline Shelekhova et al. (20) & 1 & 70 & $\mathrm{~F}$ & Sinonasal cavity \\
\hline \multirow[t]{2}{*}{ Bauer et al. (21) } & 2 & 71 & $\mathrm{~F}$ & First toe of the left foot \\
\hline & & 77 & M & Parotid gland left \\
\hline Fok et al. (22) & 1 & 74 & $\mathrm{M}$ & $\begin{array}{l}\text { Soft tissue mass plantar surface } \\
\text { adjacent to left second metatarsal } \\
\text { head }\end{array}$ \\
\hline Wémeau et al. (23) & 1 & 86 & $\mathrm{~F}$ & sub maxillary \\
\hline Westerberg et al. (24) & 1 & 73 & $\mathrm{~F}$ & Sole of the right for foot \\
\hline Syed et al. (25) & 1 & 71 & $\mathrm{~F}$ & $\begin{array}{l}\text { Temporal bone (middle ear and } \\
\text { mastoid) }\end{array}$ \\
\hline \multirow[t]{3}{*}{ Fatani et al. (26) } & 3 & 81 & $\mathrm{M}$ & Femoral neck \\
\hline & & 76 & $\mathrm{~F}$ & Great toe \\
\hline & & 87 & $\mathrm{~F}$ & $\mathrm{C} 2$ \\
\hline Ledford et al. (27) & 1 & 74 & $\mathrm{M}$ & Calcaneus \\
\hline Honda et al. (28) & 1 & 73 & $\mathrm{M}$ & Neck \\
\hline Aizawa et al. (29) & 1 & 72 & M & $\mathrm{C5}$ \\
\hline Jerkovich et al. (30) & 1 & 70 & $\mathrm{~F}$ & 3rd metacarpal bone left hand \\
\hline Tajima et al. (31) & 1 & 77 & M & Left parotid gland \\
\hline Lee et al. (32) & 1 & 73 & M & Femur \\
\hline \multirow[t]{2}{*}{ Paul et al. (33) } & 2 & 74 & $\mathrm{~F}$ & Right foot \\
\hline & & 72 & $\mathrm{~F}$ & Distal end of right femur \\
\hline Gambhir (34) & 1 & 70 & M & Superior mediastinum at D1/D2 levels \\
\hline Chazal et al. (35) & 1 & 70 & $\mathrm{~F}$ & Second phalanges right foot \\
\hline
\end{tabular}

Signs and symptoms

NA

Rt. Hip pain

NA

Bone pain and muscle weakness

Myalgia

Hip fracture

Hip fracture

Skeletal pain

Itching sensation, kyphosis and distorted arms and legs

Leg pain, walking difficulties, fracture of ribs and foot

NA

Fractures multiple sites and osteoarthritis of the hip Back pain and hip fracture left Limb pain left lower, proximal myopathy

Rib and vertebral fracture

Multiple site fractures and muscle weakness

Hearing loss, facial nerve palsy

Bone pain and fractures

Bone pain, muscle weakness, fractures (lumbar, vertebral and pelvis)

Femur metastasis

Bon pain, proximal muscle weakness Weakness

Diffuse bone pain

Myalgia

NA

Refractory bone pain and muscle weakness

Bone pain, proximal muscle weakness Bone pain

NA

Multiple fractures and diffuse pain

\section{Treatment}

During his evaluation, the patient was treated ineffectively with potassium phosphate monobasic (Calciless) eight tablets daily and vitamin D $1000 \mathrm{IU}$. His blood phosphorus levels remained consistently low despite this treatment modality. According to above investigation, the patient was referred to the orthopedic surgical department and a guided ultrasound wide resection of the tumor was performed. Histopathological examination disclosed fat tissue with proliferation of bland spindle cells with numerous blood vessels, amorphous matrix deposition and few calcifications without atypia and mitosis. The margins were free of tumor. These findings were consistent with benign PMT (Fig. 2).

\section{Follow-up and outcome}

Three months after surgery, his blood phosphorus levels and 24-h phosphorus urine collection were normalized without any treatment. 
Table 2 Tumor localization according to different regions.

\begin{tabular}{lcccc}
\hline Localization of primary tumor & & Total number & & Sex F/M \\
\cline { 1 - 1 } Head and neck & & & $6 / 4$ \\
Upper limb & & & $2 / 2$ \\
Lower limb and pelvis & & & $7 / 7$ \\
Others (mediastinum, & & & \\
$\quad$ abdomen and spine) & 33 & & $17 / 3$ \\
Total number of patients & &
\end{tabular}

\section{Discussion}

PMT represents a rare entity especially among elderly patients. The diagnosis is usually delayed due to multiple factors including vague signs and symptoms, difficulty in tumor localization and histological identification.

PMTs secrete proteins such as FGF-23, FGF-7, frizzeled-related protein 4 and matrix extracellular phosphoglycoprotein (8). FGF-23 represents the only clinically relevant protein among them, its main action is by inhibiting the sodium phosphate renal co-transporters and the suppression of $1 \alpha$ hydroxylase activity, causing decreased renal reabsorption and increased urinary phosphate excretion. As a result, in addition to hypophosphatemia, relative hyperphosphaturia, a decrease in 1,25 dihydroxyvitamin D are observed (2). It is noteworthy that recent identification of a fusion fibronectin and fibroblast growth factor receptor 1 (FN/ FGF-1) as a molecular abnormality in some tumors enhanced our knowledge in understanding not only the pathophysiological mechanisms underlying this entity, but also the transcriptional, translocational and posttranscriptional modifications, suggesting future approaches to target therapies (9).

Tumor localization represents another obstacle during patient's evaluation. PMTs are slow-growing tumors and their localization is difficult. Octreotide scintigraphy, whole-body Tc-99m sestamibi scanning, 18F-flurodexyglucose positron emission tomography (FDG-PET), $\quad{ }^{68}$ Gallium-conjugated somatostatin peptide analogs, such as ${ }^{68} \mathrm{Ga}$-DOTATATE PET/CT and ${ }^{68} \mathrm{Ga}$-DOTANOC PET/CT, whole-body MRI and CT are used for tumor localization. It is worthy of mention that ${ }^{68} \mathrm{Ga}$-DOTATATE PET/CT demonstrated the greatest sensitivity and specificity in comparison to Octreoscan SPECT/CT, FDG-PET and ${ }^{18} \mathrm{~F}$ FDG-PET for tumor localization in patients with TIO $(10,11) .{ }^{68} \mathrm{Ga}$-DOTATATE PET/CT was chosen for tumor localization in this case. The scan revealed pathological uptake measuring $1.3 \mathrm{~cm}$ in the upper aspect of left shoulder subcutaneously adjacent to the coracoid process. This very rare localization was challenging for orthopedic surgeons expert in this field using intraoperative ultrasonography for precise localization and wide excision.

About 404 cases of oncogenic osteomalacia have been reported of which PMTs are the most frequent. Both genders are equally affected and most patients are between the ages of 30 and 40 years. The most common localization of PTM involves the extremities (95\%) followed by head and neck sites (5\%). Most of PMTs are localized in the lower extremities (12).

A PubMed search between the years 1990 and 2018 has been conducted using the terms 'phosphaturic mesenchymal tumor', 'tumor-induced osteomalacia' and 'oncogenic osteomalacia'. Our search focused on reported cases among elderly patients age $\geq 70$ years, tumor localization, the presence or absence of signs and symptoms such as bone pain, muscle weakness and pathological fractures as well.

We had identified 33 cases with PMTs among elderly patients age $\geq 70$ years old with mean age (mean age 77.2 years), the female-to-male ratio was $1.35: 1$. Of these, 14 cases $(42.4 \%)$ with tumor localization in the pelvis and lower extremity, 14 cases (42.4\%) in the head, neck and upper limb, of which ten cases (33.3\%) with tumor localized in the head and neck, the remaining four cases (16.2\%), the tumor was localized in other sites such as mediastinum, abdominal wall and spine. Unlike previously reported data - where tumor localization was predominantly in the lower extremities - our search demonstrated that PMTs among elderly patients are present at a higher rate in the head and neck and with equal number of cases in the pelvis and lower extremities as well as in the head, neck and upper limb (Tables 1 and 2).

In the case presented in this manuscript, the tumor was located in the upper aspect of the left shoulder adjacent to the coracoid process. To the best of our knowledge, this tumor localization was unique and the first to be reported in the literature. Furthermore, surgical resection was challenging for the surgeon and guided intraoperative ultrasonography was used in order to perform a successful wide resection.

\section{Conclusions}

The diagnosis of PMTs should be considered among elderly patients presented with osteomalacia. Reviewing the literature, head and neck tumor localization is frequent among this group of patients and should be taken into account. Performing wide resection of the tumor represents an important matter for cure and preventing recurrence. 


\section{Declaration of interest}

The authors declare that there is no conflict of interest that could be perceived as prejudicing the impartiality of the research reported.

\section{Funding}

This article did not receive any specific grant from any funding agency in the public, commercial or not-for-profit sector.

\section{Patient consent}

Written informed consent for publication of clinical details and clinical images was obtained from the patient.

\section{Author contribution statement}

Zaina $\mathrm{A}$ is the main endocrinologist physician who followed the patient and reviewed and edited the manuscript. Nikomarov D performed the surgery. Weiler-Sagie $M$ was responsible for imaging-related aspect of the case. Roguin Maor $\mathrm{N}$ was responsible for literature reviewing and preparing the manuscript. All authors approved the final draft of the report.

\section{Acknowledgments}

Thanks and appreciations for the Endocrinology Laboratory Division at Sheba Medical Center and the Endocrinology Laboratory Division at Clalit Healthcare Medical services at Haifa and Western Galilee District.

\section{References}

1 Fukumoto S, Ozono K, Michigami T, Minagawa M, Okazaki R, Sugimoto T, Takeuchi Y \& Matsumoto T. Pathogenesis and diagnostic criteria for rickets and osteomalacia - proposal by an expert panel supported by Ministry of Health, Labour and Welfare, Japan, The Japanese Society for Bone and Mineral Research and The Japan Endocrine Society. Endocrine Journal 201562 665-671. (https://doi org/10.1507/endocrj.EJ15-0289)

2 Hautmann AH, Hautmann MG, Kölbl O, Herr W \& Fleck M. Tumorinduced osteomalacia: an up-to-date review. Current Rheumatology Reports 201517 512. (https://doi.org/10.1007/s11926-015-0512-5)

3 Chong WH, Molinolo AA, Chen CC \& Collins MT. Tumour-induced osteomalacia. Endocrine-Related Cancer 201118 R53-R77. (https:// doi.org/10.1530/ERC-11-0006)

4 Folpe AL, Fanburg-Smith JC, Billings SD, Bisceglia M, Bertoni F, Cho JY, Econs MJ, Inwards CY, Jan de Beur SM, Mentzel T, et al. Most osteomalacia-associated mesenchymal tumours are a single histopathologic entity: an analysis of 32 cases and a comprehensive review of the literature. American Journal of Surgical Pathology 200428 1-30. (https://doi.org/10.1097/00000478-200401000-00001)

5 Aziz KT, McCarthy EF \& Morris CD. Oncogenic osteomalacia secondary to a metastatic phosphaturic mesenchymal tumor in the talus: a case report and review of the literature. JBJS Case Connector 20177 e40. (https://doi.org/10.2106/JBJS.CC.16.00172)

6 Fukumoto S \& Yamashita T. Fibroblast growth factor (FGF)-23 and hypophosphatemic rickets/osteomalacia. Endocrine Journal 200148 603-610. (https://doi.org/10.1507/endocrj.48.603)

7 Hana T, Tanaka S, Nakatomi H, Shojima M, Fukumoto S, Ikemura M \& Saito N. Definitive surgical treatment of osteomalacia induced by skull base tumor and determination of the half-life of serum fibroblast growth factor 23. Endocrine Journal 201764 1033-1039. (https://doi.org/10.1507/endocrj.EJ17-0177)

8 Habra MA, Jimenez C, Huang SC, Cote GJ, Murphy WA Jr, Gagel RF $\&$ Hoff AO. Expression analysis of fibroblast growth factor-23, matrix extracellular phosphoglycoprotein, secreted frizzledrelated protein-4, and fibroblast growth factor-7: identification of fibroblast growth factor-23 and matrix extracellular phosphoglycoprotein as major factors involved in tumor-induced osteomalacia. Endocrine Practice 200814 1108-1114. (https://doi. org/10.4158/EP.14.9.1108)

9 Tajima S \& Fukayama M. Fibroblast growth factor receptor 1 (FGFR1) expression in phosphaturic mesenchymal tumors. International Journal of Clinical and Experimental Pathology 20158 9422-9427.

10 El-Maouche D, Sadowski SM, Papadakis GZ, Guthrie L, CottleDelisle C, Merkel R, Millo C, Chen CC, Kebebew E \& Collins MT. 68Ga-DOTATATE for tumor localization in tumor-induced osteomalacia. Journal of Clinical Endocrinology and Metabolism 2016 101 3575-3581. (https://doi.org/10.1210/jc.2016-2052)

11 Chua SC, O'Connor SR, Wong WL \& Ganatra RH. Case report: solitary plasmacytoma of bone with oncogenic osteomalacia: recurrence of tumour confirmed by PET/CT. A case report with a review of the radiological literature. British Journal of Radiology 2008 81 e110-e114. (https://doi.org/10.1259/bjr/58168443)

12 Jiang Y, Xia WB, Xing XP, Silva BC, Li M, Wang O, Zhang HB, Li F, Jing HL, Zhong DR, et al. Tumor-induced osteomalacia: an important cause of adult-onset hypophosphatemic osteomalacia in China: report of 39 cases and review of the literature. Journal of Bone and Mineral Research 201227 1967-1975. (https://doi.org/10.1002/ jbmr.1642)

13 Park YK, Unni KK, Beabout JW \& Hodgson SF. Oncogenic osteomalacia: a clinicopathologic study of 17 bone lesions. Journal of Korean Medical Science 19949 289-298. (https://doi.org/10.3346/ jkms.1994.9.4.289)

14 Baronofsky SI, Kalbhen CL, Demos TC \& Sizemore GW. Oncogenic osteomalacia secondary to a hemangiopericytoma of the hip: case report. Canadian Association of Radiologists Journal 199950 26-28.

15 Dupond JL, Mahammedi H, Prié D, Collin F, Gil H, Blagosklonov O, Ricbourg B, Meaux-Ruault N \& Kantelip B. Oncogenic osteomalacia: diagnostic importance of fibroblast growth factor 23 and F-18 fluorodeoxyglucose PET/CT SCAN for the diagnosis and follow-up in one case. Bone 200536 375-378. (https://doi.org/10.1016/j. bone.2005.01.001)

16 Vollbrecht JE \& Rao DS. Images in clinical medicine. Tumor-induced osteomalacia. New England Journal of Medicine $20083 \mathbf{3 8} 1282$. (https://doi.org/10.1056/NEJMicm066066)

17 Kenealy H, Holdaway I \& Grey A. Occult nasal sinus tumours causing oncogenic osteomalacia. European Journal of Internal Medicine 200819 516-519. (https://doi.org/10.1016/j.ejim.2008.01.011)

18 Yun KI, Kim DH \& Pyo SW. A phosphaturic mesenchymal tumor of the floor of the mouth with oncogenic osteomalacia: report of a case. Journal of Oral and Maxillofacial Surgery 200967 402-405. (https:// doi.org/10.1016/j.joms.2008.01.007)

19 Savage CR \& Zimmer LA. Oncogenic osteomalacia from pterygopalatine fossa mass. Journal of Laryngology and Otology 2009 123 1052-1054. (https://doi.org/10.1017/S0022215109004927)

20 Shelekhova KV, Kazakov DV \& Michal M. Sinonasal phosphaturic mesenchymal tumor (mixed connective tissue variant): report of 2 cases. American Journal of Surgical Pathology 201034 596-597. (https://doi.org/10.1097/PAS.0b013e3181d594fa)

21 Bauer C, Brücker R, Bützberger S \& Schmid C. Hypophosphataemiainducing mesenchymal tumour in the foot. BMJ Case Reports 20106 bcr0620092034. (https://doi.org/10.1136/bcr.06.2009.2034)

22 Fok AW \& Ng TP. Osteomalacia: a case series of patients with atypical clinical orthopaedic presentations. Hong Kong Medical Journal 2010 $16476-479$. 
23 Mékinian A, Ladsous M, Balavoine AS, Carnaille B, Aubert S, Soudan B \& Wémeau JL. Curative surgical treatment after inefficient long-acting somatostatin analogues therapy of a tumor-induced osteomalacia. Presse Medicale 201140 309-313. (https://doi. org/10.1016/j.lpm.2010.10.011)

24 Westerberg P-A, Linde T, Vanderschueren D, Billen J, Jans I \& Ljunggren Ö. Oncogenic osteomalacia illustrating the effect of fibroblast growth factor 23 on phosphate homeostasis. Clinical Kidney Journal 20125 240-243. (https://doi.org/10.1093/ckj/sfs031)

25 Syed MI, Chatzimichalis M, Rossle M \& Huber AM. Recurrent phosphaturic mesenchymal tumour of the temporal bone causing deafness and facial nerve palsy. Journal of Laryngology and Otology 2012126 721-724. (doi:10.1017/S0022215112000989)

26 Fatani HA, Sunbuli M, Lai SY \& Bell D. Phosphaturic mesenchymal tumor: a report of 6 patients treated at a single institution and comparison with reported series. Annals of Diagnostic Pathology 2013 17 319-321. (https://doi.org/10.1016/j.anndiagpath.2012.06.005)

27 Ledford CK, Zelenski NA, Cardona DM, Brigman BE \& Eward WC. The phosphaturic mesenchymal tumor: why is definitive diagnosis and curative surgery often delayed? Clinical Orthopaedics and Related Research 2013471 3618-3625. (https://doi.org/10.1007/s11999-013-3178-1)

28 Honda R, Kawabata Y, Ito S \& Kikuchi F. Phosphaturic mesenchymal tumor, mixed connective tissue type, non-phosphaturic variant: report of a case and review of 32 cases from the Japanese published work. Journal of Dermatology 201441 845-849. (https://doi. org/10.1111/1346-8138.12602)

29 Nakamura T, Aizawa T, Hoshikawa T, Ozawa H, Ito N, Fukumoto S, Itoi E \& Kokubun S. Tumor-induced osteomalacia caused by phosphaturic mesenchymal tumor of the cervical spine.Journal of Orthopaedic Science 201520 765-771. (https://doi.org/10.1007/ s00776-014-0540-4)

30 Jerkovich F, Moncet D, Babini S, Zoppi JA, Graciolli F \& Oliveri B. Oncogenic osteomalacia. Report of two cases. Medicina 201575 37-40.

31 Tajima S \& Fukayama M. Possibility of D2-40 as a diagnostic and tumor differentiation-suggestive marker for some of phosphaturic mesenchymal tumors. International Journal of Clinical and Experimental Pathology 20158 9390-9396.

32 Lee JC, Su SY, Changou CA, Yang RS, Tsai KS, Collins MT, Orwoll ES, Lin CY, Chen SH, Shih SR, et al. Characterization of FN1-FGFR1 and novel. Modern Pathology 201629 1335-1346. (https://doi. org/10.1038/modpathol.2016.137)

33 Satyaraddi A, Cherian KE, Shetty S, Kapoor N, Jebasingh FK, Cherian VM, Hephzibah J, Prabhu AJ, Thomas N \& Paul TV. Musculoskeletal oncogenic osteomalacia-an experience from a single centre in South India. Journal of Orthopaedics 201714 184-188. (https://doi.org/10.1016/j.jor.2016.12.010)

34 Singh D, Chopra A, Ravina M, Kongara S, Bhatia E, Kumar N, Gupta S, Yadav S, Dabadghao P, Yadav R, et al. Oncogenic osteomalacia: role of Ga-68 DOTANOC PET/CT scan in identifying the culprit lesion and its management. British Journal of Radiology 201790 20160811. (https://doi.org/10.1259/bjr.20160811)

35 Chazal T, Khanine V, Lidove O, Godot S \& Ziza JM. Tumor-induced osteomalacia caused by a late-revealing phosphaturic mesenchymal tumor. Revue de Medecine Interne 201738 412-415. (https://doi. org/10.1016/j.revmed.2016.08.020)

Received in final form 25 January 2019 Accepted 11 April 2019 